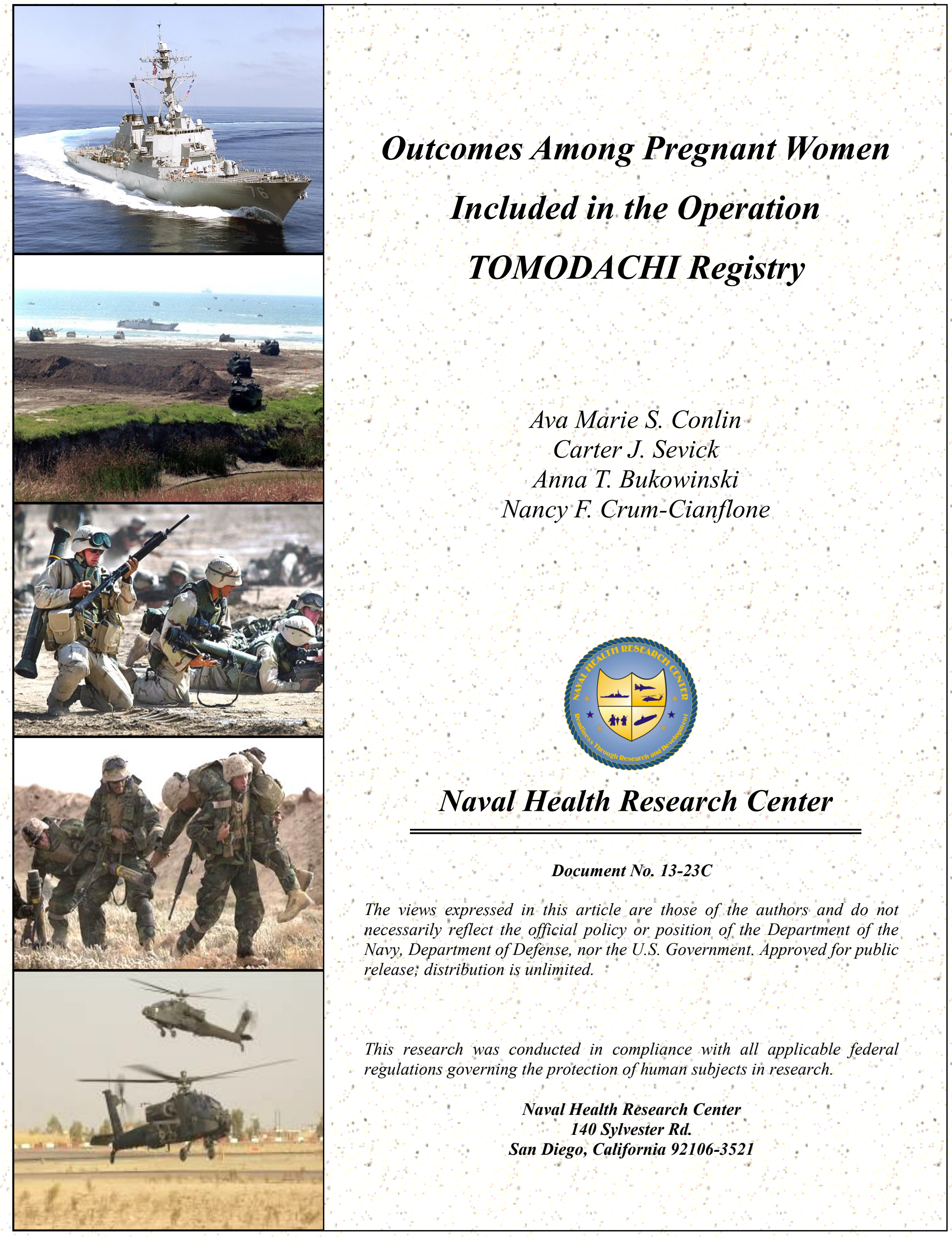




\section{Outcomes Among Pregnant Women Included in the Operation TOMODACHI Registry}

Ava Marie S. Conlin, DO, MPH; Carter J. Sevick, MS; Anna T. Bukowinski, MPH; Nancy F. Crum-Cianflone, MD, MPH

Naval Health Research Center

Deployment Health Research Department

140 Sylvester Road

San Diego, CA 92106-3521

This represents report 13-3C, supported by the Department of Defense, under work unit no. 60504. The views expressed in this article are those of the authors and do not reflect the official policy or position of the Department of the Navy, Department of Defense, or the US Government. This research has been conducted in compliance with all applicable federal regulations governing the protection of human subjects in research (Protocol NHRC.1999.0003).

Distribution Statement: Approved for public release; distribution is unlimited. 


\section{Outcomes among Pregnant Women Included in the Operation TOMODACHI Registry}

In August 2011, personnel from the Naval Health Research Center's Deployment Health Research Department participated in the Operation TOMODACHI Registry (OTR) Workshop. The OTR is a registry for the entire Department of Defense (DoD)-affiliated population on or near the mainland of Japan following the radiation released from the Fukushima Daiichi nuclear power plant on March 11, 2011. For more information on the OTR, please visit the OTR website: https://registry.csd.disa.mil/registryWeb/Registry/OperationTomodachi/ DisplayAbout.do. As a result of our participation in the workshop and our expertise with surveillance of pregnancy and infant health outcomes among DoD beneficiaries, The DoD Birth and Infant Health Registry (based at the Naval Health Research Center) was asked by the OTR Medical and Claims Users Working Group to describe outcomes among an identified population of women captured in the OTR who were thought to be pregnant around the time of the radiation incident.

Established in 1998 at the direction of the Assistant Secretary of Defense for Health Affairs, the DoD Birth and Infant Health Registry (Registry) aims to better understand the reproductive health effects of military service. ${ }^{1}$ To accomplish this goal, the Registry provides systematic surveillance of live births to DoD beneficiaries, following infants for 1 year after birth to assess health outcomes, including birth defects and preterm birth. Outcomes are assessed using International Classification of Diseases, 9th Revision, Clinical Modification (ICD$9-\mathrm{CM})^{2}$ medical encounter codes that are assigned to both inpatient and outpatient visits at military treatment facilities and civilian institutions where care is funded through TRICARE. Allowing data to populate through the infants' first year of life means these assessments are retrospective in nature, but as data are available, the Registry is also capable of conducting prospective assessments of outcomes for clearly-defined exposed populations. Recently the Registry has also been used to evaluate pregnancy outcomes among defined populations of pregnant women with a specific exposure. This evolution of the Registry allows for the assessment of pregnancy loss and other pregnancy complications as indicated.

With approximately 100,000 live births to military beneficiaries each year, the Registry currently contains data on more than 1 million infants. The primary use of these data is to monitor the prevalence of birth defects, which are defined according to the Case Definition of the National Birth Defects Prevention Network. ${ }^{3}$ Additional uses for these data include evaluating associations of various birth outcomes with specific exposures. Registry data currently contains information on "at birth" diagnoses for infants born through 2010 and infant care through the first year of life for infants born through 2009. The time of the Japan incident is therefore not currently included in the Registry. However, Registry staff received a list of the population in question and, by applying definitions to medical data in the MHS Data Repository, were able to determine the rates of pregnancy loss and live births among the identified pregnant women, as well as the rates of birth defects, growth problems in utero, and preterm birth, and the sex ratio, among their infants. After allowing adequate time for the March 2011 pregnancies to progress to an outcome and for the electronic medical encounter data to be appropriately updated, the Registry presents the following findings.

Of the 617 women that were present on the initial list received in the Fall of 2011,7 were determined to be duplicates. Of the remaining 610,607 were able to be adequately identified by sponsor social security number or Electronic Data Interchange Personal Identifiers in order to locate their electronic medical encounter data. Of these, 604 were determined to have had a pregnancy at some point between 2010 and 2012. Five hundred eighty-eight were classified as having been pregnant at or around the time of the incident, determined by having care in Japan or being enrolled for care in Japan, and having a pregnancy that included a date within the range of March 11, $2011+60$ days or, in the case of a pregnancy with an unknown result, had pregnancy care ending within 30 days prior to March 11, 2011. These 588 women had a total of 590 pregnancies 


\section{Information Sheet}

considered to be the potentially-exposed group of pregnancies. The vast majority of pregnancies (71.5\%) were among military dependents, while $22.5 \%$ were among military sponsors, and $5.9 \%$ were among non-military personnel.

Table 1. Status of Potentially Exposed Pregnancies

\begin{tabular}{lrrc}
\hline Pregnancy status & $\mathbf{n}$ & $\%$ & $(95 \% \mathbf{C l})^{\mathrm{a}}$ \\
\hline Total pregnancies & 590 & & \\
Live delivery $^{\mathrm{b}}$ & 556 & 96.5 & $(94.7,97.9)$ \\
Loss $^{\mathrm{b}}$ & 20 & 3.5 & $(2.1,5.3)$ \\
Induced abortion & 3 & - & - \\
Unknown & 11 & - & - \\
\hline
\end{tabular}

${ }^{a} 95 \%$ confidence intervals computed using exact (Clopper-Pearson) methods. ${ }^{b}$ Percents and confidence intervals for live deliveries and losses do not include induced abortions or unknown outcomes.
Table 1 shows the status of potentially-exposed pregnancies. Pregnancy outcomes include live delivery, spontaneous loss, and induced abortion. Remaining pregnancies are classified as unknown, likely due to eligibility for care ending prior to the pregnancy outcome and/or lack of visibility of a pregnancy outcome in the electronic medical data/records. Overall, the live delivery rates are quite high and the spontaneous loss rates are quite low. This finding could be the result of how the initial list of affected women was generated, preferentially including those who were seeking prenatal care and had already progressed past the first few weeks of pregnancy when spontaneous loss is most common. Limiting

pregnancies to those that began in a 60-day window following the incident (11MAR2011 - 10MAY2011) resulted in 10 losses and 66 live deliveries for a loss rate of $13.16 \%(95 \% \mathrm{Cl}, 6.49-22.87)$, which is within the expected range. A few induced abortions were seen, but their visibility in the DoD medical data is variable, so complete capture may not be possible.

Table 2. Health Outcomes among Liveborn Infants With Potential In-Utero Exposure Compared to "at Birth" Health Outcomes among DoD Birth and Infant Health Registry Births ${ }^{a}$

\begin{tabular}{|c|c|c|c|c|c|c|c|}
\hline \multirow[t]{2}{*}{ Infant outcomes } & \multicolumn{3}{|c|}{ OTR } & \multicolumn{4}{|c|}{ Registry at birth ${ }^{a}$} \\
\hline & $\mathbf{n}$ & $\%$ & $(95 \% \mathrm{Cl})^{\mathrm{b}}$ & $\%$ & $(95 \% \mathrm{Cl})$ & OR & $(95 \% \mathrm{Cl})$ \\
\hline Total infants & 523 & & & & & & \\
\hline Any birth defect & 11 & 2.1 & $(1.1,3.7)$ & 2.01 & $(1.93,2.10)$ & 1.05 & $(0.54,1.81)$ \\
\hline Growth problems in-utero & 15 & 2.9 & $(1.6,4.7)$ & 1.83 & $(1.75,1.92)$ & 1.58 & $(0.90,2.55)$ \\
\hline \multirow[t]{2}{*}{ Preterm birth } & 32 & 6.1 & $(4.2,8.5)$ & 7.72 & $(7.56,7.89)$ & 0.78 & $(0.53,1.10)$ \\
\hline & $\mathbf{n}$ & $\begin{array}{c}\text { Sex } \\
\text { ratio }\end{array}$ & $(95 \% \mathrm{Cl})^{\mathrm{C}}$ & $\begin{array}{c}\text { Sex } \\
\text { ratio }\end{array}$ & $(95 \% \mathrm{Cl})$ & OR & $(95 \% \mathrm{Cl})$ \\
\hline Male birth & 262 & 1.0 & $(0.8,1.2)$ & 1.05 & $(1.04,1.06)$ & 0.95 & $(0.80,1.13)$ \\
\hline
\end{tabular}

OTR, Operation TOMODACHI Registry; OR, odds ratio.

${ }^{a}$ Registry infants included if gestation occurred at any time during the 11MAR2009 - 10MAY2009 window.

b $95 \%$ confidence intervals computed using exact (Clopper-Pearson) methods.

${ }^{\mathrm{c}} 95 \%$ confidence interval computed using exact methods.
Table 2 shows outcomes of the 523 liveborn infants who had adequate identifying information to be included in additional analyses. Rates for each of the outcomes are comparable to rates seen within the Registry when restricting the Registry to "at birth" diagnoses. Examination of the specific birth defects revealed a variety of defects including atrial septal

defect, pulmonary valve atresia or stenosis, cleft lip with and without cleft palate, obstructive genitourinary defect, reduction deformity, congenital hip dislocation, diaphragmatic hernia, and hypospadias, and no common pathophysiology was identified.

Although analyses to date are reassuring, additional efforts are planned to identify women that may have been in the area at the time, but were not included in the initial rosters; identify other births in Japan whose dates 


\section{Information Sheet}

would indicate that the pregnancy began on or prior to March 11, 2011; and look for women who had any pregnancy-related care in Japan at the time of the incident, or who were enrolled in the area and had any type of medical care in Japan, and later had a pregnancy or birth elsewhere whose dates would indicate that the pregnancy was ongoing in Japan at the time of the incident. Additionally, for identified liveborn infants, there are plans to follow them through their first year of life and potentially beyond, depending on the needs of the OTR Working Group, so that outcomes are not limited to those identified at birth. Ideally, additional exposure information will become available that would indicate the magnitude of potential exposure (i.e., proximity to the power plant, time in the area, etc.) and could contribute to a greater understanding of current and future analyses.

\section{References}

1. Ryan MAK, Pershyn-Kisor MA, Honner WK, Smith TC, Reed RJ, Gray GC. The Department of Defense Birth Defects Registry: overview of a new surveillance system. Teratology. 2001;64(S1):S26-S29.

2. National Center for Health Statistics. International Classification of Diseases, Ninth Revision, Clinical Modification (ICD-9-CM). Washington, DC: Government Printing Office; 2011.

3. Sever, LE, ed. Guidelines for Conducting Birth Defects Surveillance. Atlanta, GA: National Birth Defects Prevention Network, Inc.; 2004. 


\section{Information Sheet}

\section{References}

1. Sever, LE, ed. Guidelines for Conducting Birth Defects Surveillance. Atlanta, GA: National Birth Defects Prevention Network, Inc.; 2004.

2. National Center for Health Statistics. International Classification of Diseases, Ninth Revision, Clinical Modification (ICD-9-CM). Washington, DC: Government Printing Office; 2011.

3. Ryan MAK, Pershyn-Kisor MA, Honner WK, Smith TC, Reed RJ, Gray GC. The Department of Defense Birth Defects Registry: overview of a new surveillance system. Teratology. 2001;64(S1):S26-S29. 


\section{REPORT DOCUMENTATION PAGE}

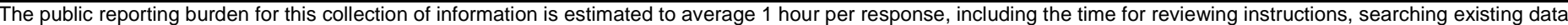

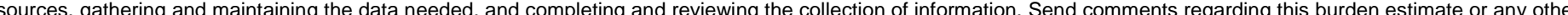
aspect of this collection of information, including suggestions for reducing the burden, to Washington Headquarters Services, Directorate for Information Operations and

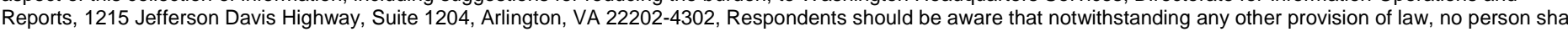

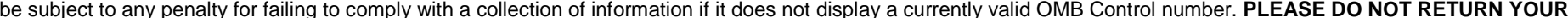
FORM TO THE ABOVE ADDRESS.

1. REPORT DATE (DD MM YY) 120213

2. REPORT TYPE

Technical Document
3. DATES COVERED (from - to)

Jan - Dec 2011

4. TITLE

Outcomes Among Pregnant Women Included in the Operation TOMODACHI Registry

6. AUTHORS

Conlin, Ava Marie S.; Sevick, Carter J.; Bukowinski, Anna T.; Crum-

Cianflone, Nancy $F$.

7. PERFORMING ORGANIZATION NAME(S) AND ADDRESS(ES)

Commanding Officer

Naval Health Research Center

140 Sylvester Rd

San Diego, CA 92106-3521

8. SPONSORING/MONITORING AGENCY NAMES(S) AND ADDRESS(ES)

Commanding Officer

Naval Medical Research Center

Chief, Bureau of Medicine and Surgery

503 Robert Grant Ave

(MED 00), Navy Dept

Silver Spring, MD 20910-7500

2300 E Street NW

Washington, DC 20372-5300

5b. Grant Number:

5c. Program Element Number:

5d. Project Number:

5e. Task Number:

5f. Work Unit Number:60504

8. PERFORMING ORGANIZATION REPORT NUMBER

Tech Doc No. 13-3C

10. SPONSOR/MONITOR'S ACRONYM(S) NMRC/BUMED

11. SPONSOR/MONITOR'S REPORT NUMBER(s)

\section{DISTRIBUTIONIAVAILABILITY STATEMENT}

Approved for public release; distribution is unlimited.

\section{SUPPLEMENTARY NOTES}

\section{ABSTRACT}

In August 2011, personnel from the Naval Health Research Center's Deployment Health Research Department participated in the Operation TOMODACHI Registry (OTR) Workshop. The OTR is a registry for the entire Department of Defense (DoD)-affiliated population on or near the mainland of Japan following the radiation released from the Fukushima Daiichi nuclear power plant on March 11, 2011.

As a result of our participation in the workshop and our expertise with surveillance of pregnancy and infant health outcomes among DoD beneficiaries, the DoD Birth and Infant Health Registry (based at the Naval Health Research Center) was asked by the OTR Medical and Claims Users Working Group to describe outcomes among an identified population of women captured in the OTR who were thought to be pregnant around the time of the radiation incident.

\section{SUBJECT TERMS}

military personnel, registries, epidemiology

16. SECURITY CLASSIFICATION OF:

a. REPOR

UNCL

\section{LIMITATION}

OF ABSTRACT

UNCL

UNCL
18. NUMBER OF PAGES

4 18a. NAME OF RESPONSIBLE PERSON Commanding Officer

18b. TELEPHONE NUMBER (INCLUDING AREA CODE) COMM/DSN: (619) 553-8429 